\title{
ANÁLISIS GEOGRÁFICO DE LAS TORMENTAS SEVERAS EN EL LITORAL MEDITERRÁNEO ESPAÑOL
}

\author{
Jonathan GÓMEZ CANTERO \\ Universidad de Alicante. Doctorando. \\ jonathan.cantero@geografos.org
}

\section{RESUMEN}

Las tormentas severas, entre ellas los sistemas y complejos convectivos de mesoescala (SCM y CCM), son uno de los fenómenos atmosféricos que más impacto causan en el litoral mediterráneo español. De forma frecuente estos eventos son los culpables de catástrofes de índole humana. En este trabajo se analizarán algunos de los eventos más relevantes ocurridos desde 1982 para entender su génesis, hacer una aproximación climática y trazar las trayectorias y retrotrayectorias que siguen en su desplazamiento horizontal, así como el impacto que tienen. Estos fenómenos deben analizarse desde la Geografía con aplicación al territorio y a la sociedad para mitigar sus daños y poder establecer escenarios de futuro en un contexto de cambio climático.

Palabras clave: Tormenta, sistema convectivo de mesoescala (SCM), complejo convectivo de mesoescala (CCM), cambio climático.

\begin{abstract}
Severe storms, included mesoscale convective systems and complexes, are one of the atmospheric phenomena that cause more impact on the Spanish Mediterranean coast. Frequently these extreme events are to blame for human and economic losses. This paper will discuss some of the most relevant events occurred since 1982, focusing on understand their genesis, making a climate approach and plotting the trajectories and back-trajectories in the horizontal displacement, and the impacts that it has. This natural hazard should be analyzed from the Geography with a territorial and social application to mitigate damage and be able to study future scenarios in a climate change context.
\end{abstract}

Key words: Storm, mesoescale convective complexes, mesoescale convective complexes, climate change.

\section{INTRODUCCIÓN}

La costa mediterránea española está situada geográficamente en una zona de perfecta confluencia marítima para la formación de potentes sistemas convectivos mesoescalares, y se ve afectada de manera regular por estos fenómenos durante todo el año, especialmente en otoño cuando llegan grandes masas de aire frío en altura. La zona de transición climática entre las masas de aire cálidas y húmedas de génesis mediterráneas y las frías del norte hace que la zona se encuentre en un campo de inestabilidad durante buena parte del año, siendo una de las zonas de Europa más afectadas si hacemos una medida en días/año (Capel, 2000). La gran extensión que alcanzan 
estos fenómenos y sus varias horas de vida hacen que sea necesario contar con una zona de estudio lo suficientemente amplia como para englobar a varios a lo largo de todo su ciclo, por lo que aquí se ha tenido en cuento todo el arco mediterráneo español.

El estudio del comportamiento, génesis y evolución de los SCM y CCM es vital para mitigar sus daños. Estos fenómenos atmosféricos de gran virulencia causan graves daños en el territorio, y en ocasiones han sido los culpables de las mayores pérdidas económicas y humanas en la zona de estudio, además de haber representado cantidades de precipitación récord. Hay que añadir, que pese a que desde la Meteorología hay técnicas para diferenciarlos: a) dimensiones mesoescalares de la estructura tormentosa, que se diferencia por la extensión del área definida por la isoterma de $-32^{\circ} \mathrm{C}$ en los topes nubosos, b) Ciclo de vida de varias horas, c) precipitaciones intensas y aparato eléctrico (Maddox, 1980), en el campo de la Geografía no hay ninguna metodología, pero es importante añadir que su impacto territorial y pluviométrico puede ser idéntico, por lo que no se le ha prestado mayor relevancia en el trabajo y se han tratado indistintamente.

Para este artículo se analizarán distintos fenómenos ocurridos a partir de 1982 ya que fue a partir del 20 de octubre de este año cuando se observó el primero de estos fenómenos en Europa (Armengot y Pérez, 1983), concretamente afectando a la Comunidad Valenciana. Partiendo de esta premisa, se tratará de hacer una aproximación por satélite y establecer la climatología de los casos; en este sentido se cree que al tener un desplazamiento horizontal y verse influenciado por los vientos cargados de humedad del mediterráneo, podría establecerse una correlación en su punto de origen y desplazamiento, en función de cada situación sinóptica, lo que además serviría para crear las trayectorias que podría seguir ante una situación determinada, del mismo modo que se hace con los huracanes, de manera que serviría para la prevención y mitigación de daños, así como para el establecimiento de sistemas de alerta temprana.

\section{MÉTODOS Y MATERIALES}

La consecución de los objetivos propuestos en esta investigación y la rigurosidad de los datos exige trabajar con fuentes de muy diferente índole. Desde aquellas contenidas en la Agencia Estatal de Meteorología (antiguo INM) y otras instituciones con información climática y meteorológica de rigor como el SAIH (Sistema Automático de Información Hidrológica). La información indirecta registrada en documentos elaborados por múltiples organismos, profesionales y artículos de prensa que hayan permitido estudiar las zonas afectadas y en medida de lo posible la hora a la que ocurría (Fig. 1).

Desde el punto de vista de las fuentes de información directa, debemos señalar la importancia de las imágenes satelitales, especialmente las de canal infrarrojo para así caracterizar el tamaño de los SCM y CCM (Riosalido, 1990) tal y como hemos visto líneas atrás y además, ubicarlos en el tiempo y en espacio. Por otro lado, se harán indispensables las imágenes de radar (por sus siglas en inglés Radio Detection and Ranging) para detectar y medir meteoros naturales como precipitaciones líquidas, sólidas... Ello ha hecho que ante ciertos fenómenos en los que no existía la suficiente información se hayan eliminado para no introducir así ningún ruido en la muestra y analizar los casos más seguidos. 
Para esta primera aproximación se han tenido en cuenta los siguientes fenómenos como ejemplos singulares: 20 de octubre de 1982 (derrumbe de la Presa de Tous); 3 y 4 de noviembre de 1987 (inundaciones de Gandía); 7 de septiembre de 1989 (inundaciones Vega Baja); 30 de septiembre de 1997 (ciudad de Alicante); 17 de agosto de 2003 (Cataluña); 4 de octubre de 2007 (costa de Murcia) y 14 de octubre de 2007 (Baleares).

Una vez que se tenía la caracterización de las imágenes y las zonas afectadas, se han cartografíado los eventos estableciendo el recorrido de los mismos sobre un mapa base. Además, una vez extraída toda la información se han podido analizar estadísticamente estos casos, la ocurrencia de estos fenómenos y las situaciones sinópticas principales para su formación.
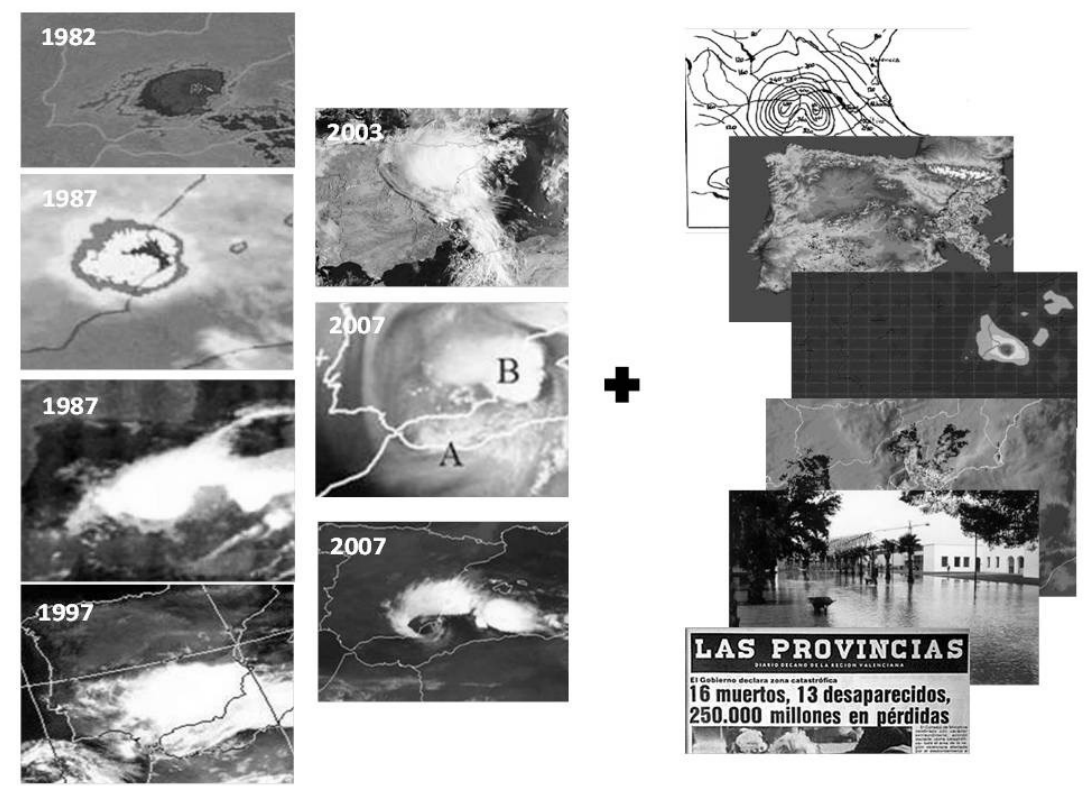

Fig. 1: Método de trabajo a partir de diversas fuentes para analizar las siete estructuras convectivas (izda.). Fuente: Elaboración propia

Además de la elaboración cartográfica se han agrupado por las estaciones del año para analizar la época con mayor frecuencia de estos fenómenos y las situaciones sinópticas dentro de las cuáles se generaron, y se han clasificado entre Gota Fría/ DANA; vaguada y vaguada retrógrada. Esta clasificación a su vez resultó de gran interés porque nos mostraba una mayor información para estudiar donde se ubicaba el centro depresionario en el momento que se gestaban las estructuras convectivas mesoescalares, visible en los mapas de $500 \mathrm{hPa}$ y $300 \mathrm{hPa}$.

\section{RESULTADOS}

El resultado cartográfico obtenido nos mostró que la trayectoria seguida por los SCM y CCM sigue el canal que aporte mayor energía y alimentación (Fig. 2). En to- 
dos los casos salvo en el de 2003, las estructuras se desplazan hacia el mar siguiendo la entrada de los vientos cargados de humedad. En el caso de 1982 sobre el embalse de Tous, debido a la orografía y una velocidad de viento superior en algunos momentos a los $80 \mathrm{~km} / \mathrm{h}$ se produjo un "efecto anclaje" que hizo que la tormenta permaneciera varias horas sobre el mismo punto lo que ayudó a que se acumularan en algunos puntos más de 600 litros en 24 horas. En el caso del SCM de 2003 se desplaza hacia y sobre el interior de Cataluña, los vientos procedentes del mediterráneo eran flojos, inferiores a los $40 \mathrm{~km} / \mathrm{h}$ y la estructura se alimenta del calor almacenado en el valle del Ebro, lo que sirvió para potenciar su energía. Ello provocó que el aparato eléctrico sea hasta hoy el récord absoluto en España con 60.201 rayos caídos en 24 horas. Destacaron especialmente las provincias de Tarragona con 13.867 descargas y Castellón con 16.548, con un máximo de 5.000 en dos horas. Su bajo aporte de humedad ayudó a que las precipitaciones acumuladas en las localidades afectadas no superasen en su mayor parte los $651 / \mathrm{m}^{2}$, una cifra que aunque abundante para recogerse en pocas horas, queda muy por debajo de las cantidades pluviométricas "normales" para eventos de esta magnitud y extensión.

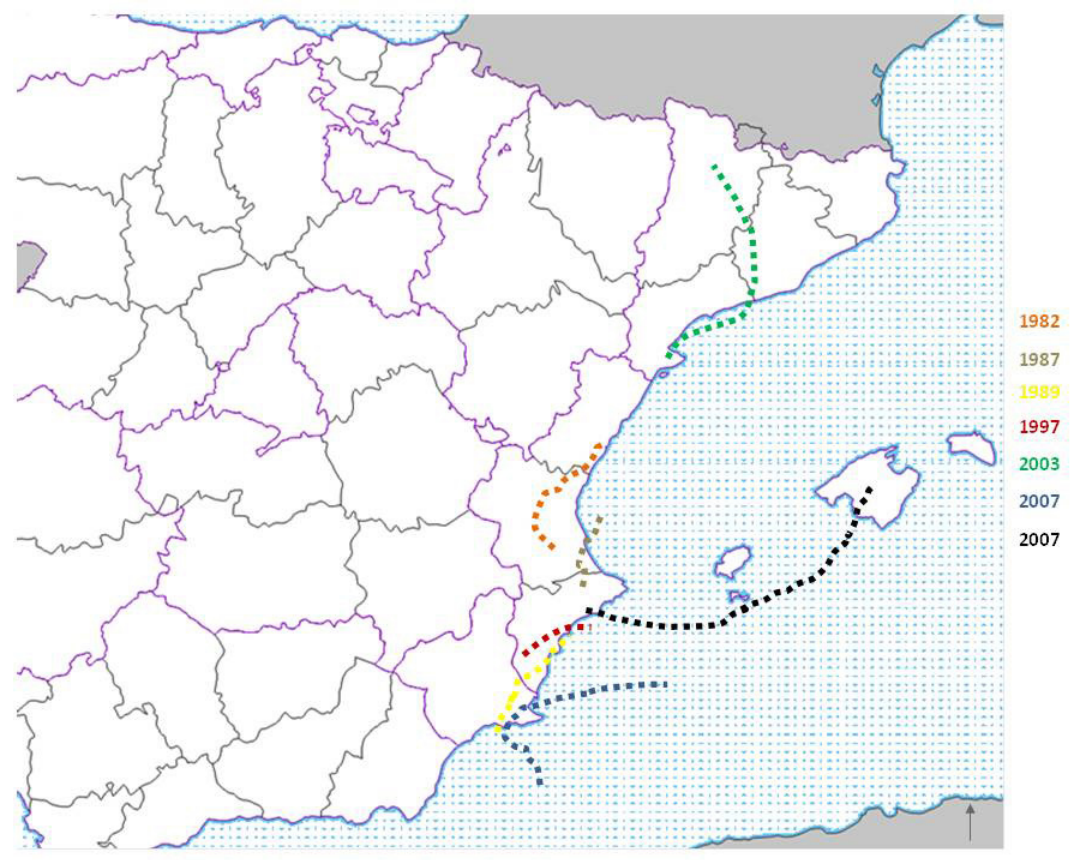

Fig. 2: Trayectorias de los SCM y CCM analizados. Fuente: Elaboración propia

\subsection{Análisis de casos}

La configuración sinóptica requiere que existe un gran contraste térmico en altura y el choque de dos masas de aire distintas que favorezcan la convección y la divergencia en altura. Todos los fenómenos analizados cumplen con esta premisa y en vista a 
los resultados son las Gotas Frías y DANA las que representan el mayor porcentaje de formación de fenómenos, seguida de vaguadas y vaguadas que retrógradas (Graf. 1), que estas últimas aunque es más difícil su configuración, presentan por su recorrido sobre el mediterráneo un gran contraste térmico con la superficie más cálida y húmeda.

Por consiguiente, la ubicación del centro depresionario de estas estructuras ha sido analizado en el momento de formación de los SCM y CMM para estudiar si se ve condicionado (Graf. 2). Los datos han sido reveladores pese a los pocos casos y se muestra una clara predisposición por la formación en los momentos en los que el núcleo frío se sitúa en el golfo de Cádiz seguido por el eje vertical sobre el mar de Alborán.

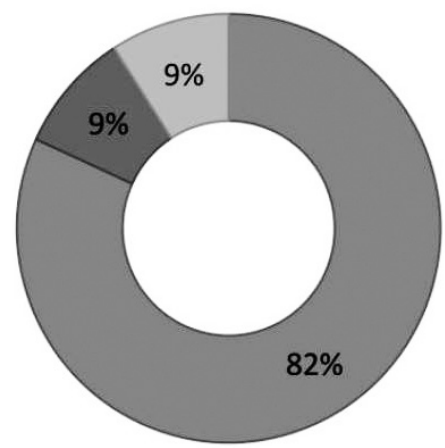

Gota fría / DANA

$\square$ Vaguada

$\square$ Vaguada retrógrada

Gráfico 1 (Izda.): Configuraciones sinópticas que albergan SCM y CCM. Fuente: Elaboración propia.

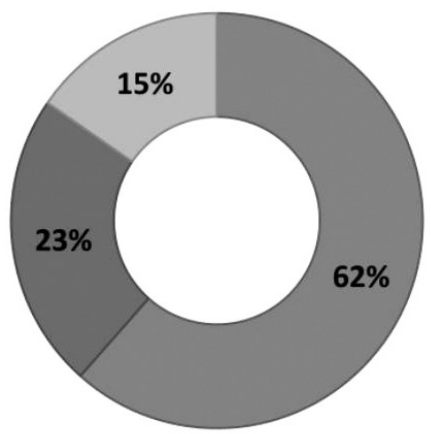

$\square$ Golfo de Cádiz

$\square$ Mar de Alborán

$\square$ Otros

Gráfico 2 (Dcha.): Ubicación del núcleo de las estructuras en el momento de su génesis visto en un mapa de 500hPa. Fuente: Elaboración propia.

Las estaciones del año en las que tenemos estos episodios son otoño (73\%) y verano (27\%) con ningún caso en invierno debido a la frialdad de las aguas del mar y a la menor convección.

Con estos datos, se ha hecho una aproximación a un mapa de riesgo por afección de SCM y CCM (Fig. 3), en función de fenómenos pasados y configuraciones atmosféricas comunes, teniendo claro los pocos casos que se pueden estudiar. 


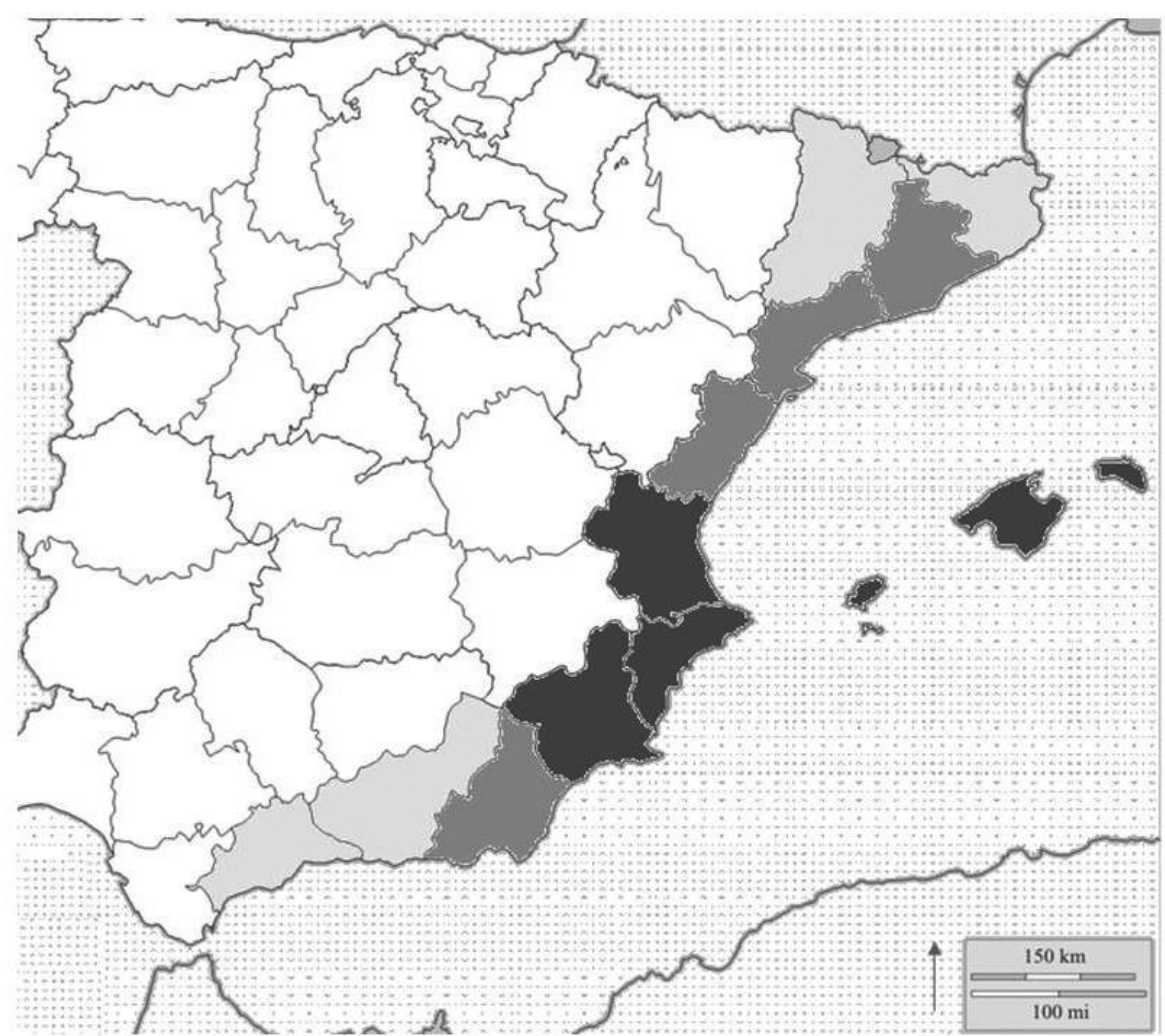

Figura 3: Mapa de riesgo por afección de estructuras convectivas mesoescalares. (Altonegro; medio - gris oscuro; bajo - grisclaro). Fuente: Elaboración propia.

\section{DISCUSIÓN}

A razón de los resultados obtenidos se ha podido establecer una alta correlación entre las estructuras convectivas y su desplazamiento en función del canal de alimentación, que además contribuye de manera llamativa en los registros de precipitación: si el viento entrante a la tormenta lo hace cargado de humedad aumenta la pluviometría, pero ello puede contribuir a desgastarlo antes y que su tiempo de duración sea menor, ya que la corriente descendente puede llegar a ser mayor que la entrante, pero sin olvidar el riesgo para la población ante estas lluvias torrenciales. El caso del año 2003 es paradigmático y muestra que los aportes de humedad no son obligatorios y si se dispone de energía suficiente puede mantenerse como estructura durante horas.

El desplazamiento horizontal de las estructuras es en todos los casos hacia el mar menos en 2003. La entrada de flujos de viento húmedos desde el interior del Mediterráneo actúa como caudal de entrada de las células y acaban avanzando en dirección contraria al viento de superficie buscando el mayor aporte de energía. En 2003 el mayor aporte era el aire cálido del valle del Ebro. 
Los SCM y CCM en nuestro entorno de estudio, se desarrollan fundamentalmente por fuerte advección cálida en niveles bajos. De forma resumida, las condiciones más favorables para el desarrollo de estas estructuras viene caracterizado por: a) una fuerte advección cálida en capas bajas; b) forzamiento sinóptico acusado en niveles bajos con un forzamiento débil o incluso negativo en niveles medios; c) fuerte inestabilidad; d) altos niveles de CAPE; e) alto contenido en humedad en toda la troposfera, con depresiones del punto de rocío inferiores a $7^{\circ} \mathrm{C}$ entre 1.000 y $500 \mathrm{hPa}$. Alto contenido de agua precipitable total; f) Posible presencia de fronteras o al menos de fuerte gradiente de temperatura potencial equivalente con orientación $\mathrm{E}-\mathrm{W}$ en niveles bajos y g) viento de componente este en niveles bajos girando hacia el SW en altura. Las Gota Fría / DANA son las que más favorecen su génesis, y la mayor parte de los casos así lo muestra. Además, cuando el centro se sitúa sobre el golfo de Cádiz aumenta el riesgo ya que la dirección de los vientos en altura favorece la convección y la cizalladura.

Es esperable que según lo modelos climáticos que apuntan a una mayor calidez de las aguas a finales del verano y principios del otoño, este tipo de estructuras puedan generarse con mayor probabilidad si se da la configuración atmosférica apropiada.

Debido a la falta de información y conocimiento de estas estructuras, la investigación en esta línea debe ser constante. El desarrollo de la nueva tecnología permite conocer mucho más de estos fenómenos e incluso poco a poco avanzar en su predicción, evitando así las sorpresas en su formación. En avance en los estudios estadísticos aún es escaso, y además de no existir un buen número de eventos catalogados, tampoco se dispone de eventos históricos que pudieran ser correlacionados con SCM y CCM.

El litoral mediterráneo español se muestra como un espacio de alto riesgo para eventos atmosféricos extremos especialmente en sus meses de otoño. Aunque aún no se ha constatado como tal la formación de huracanes, no es desmesurado indicar que los Sistemas y Complejos Convectivo de Mesoescala son al Mediterráneo español, lo que los huracanes al Golfo de México.

\section{AGRADECIMIENTOS}

A los profesores Jorge Olcina Cantos (UA) y Felipe Fernández García (UAM) que dirigen y codirigen mi Tesis doctoral sobre estos fenómenos y tan amablemente han revisado este texto.

\section{REFERENCIAS}

Armengot Serrano, R. y Pérez Cueva, A. (1983). El temporal de octubre de 1982 en el marco de las lluvias torrenciales en la cuenca baja del Júcar. Valencia. Ed. Cuadernos de Geografía.

Canalejo, M., Carretero, O., y Riosalido, R. (1993). Sistemas Convectivos de Mesoescala. Campaña Previmet Mediterráneo - 90. Nota técnica STAP Nº9. INM.

Canalejo, M., Carretero, O., y Riosalido, R. (1994). Sistemas Convectivos de Mesoescala. Campaña Previmet Mediterráneo - 92. Nota técnica STAP Nº14. INM. 
Capel Molina, J.J. (1989). Convección profunda sobre el Mediterráneo español. Lluvias torrenciales durante los días 4 al 7 de septiembre de 1989 en Andalucía Oriental, Murcia, Levante, Cataluña y Mallorca. Paralelo $37^{\circ}, \mathrm{N}^{\circ} 13$, pp. 51-79.

Capel Molina, J.J. (2000). Los sistemas convectivos de mesoescala y su influencia en la España Mediterránea. Papeles de Geografía, No 32, 2000, pp. 29-43.

Carbunaru, D., Sasu, M., Burcea S. y Bell. A. (2014). Detection hail through the three body scattering signatures and its effects on radar algorithms observed in Romania. Atmósfera. Vol. 27, No. 1. pp. 21-34.

Carretero, O., Canalejo, M., y Riosalido, R. (1993). Sistemas Convectivos de Mesoescala. Campaña Previmet Mediterráneo - 91. Nota técnica STAP No12. INM.

CEAM (2007). Informe meteorológico sobre el episodio de lluvias torrenciales del 11-12 de Octubre de 2007 en la Comunidad Valenciana. Documento en línea. 15pp. Recuperado de: http://www.uv.es/ femenia/oratge/GOTAFREDA2007/ informe lluvias 11 12 octubre.pdf

Elvira, B., Carretero, O., y Riosalido, R. (1996). Sistemas Convectivos de Mesoescala. Campaña Previmet Mediterráneo - 94. Nota técnica STAP No24. INM.

Genovés, A. y Jansá, A. (1989). Caracterización estadística de las perturbaciones mesoescalares en la región ibérico-mediterránea. Primer Simposio Nacional de Predictores del INM. Madrid, septiembre. pp. 39-49. INM

Jirak, I. L., Cotton, W. R., y McAnelly, R. L. (2003). Satellite and radar survey of mesoscale convective system development. Monthly weather review. pp.2428-2449. doi: http://dx.doi.org/10.1175/1520-0493(2003)131<2428:SARSOM >2.0.CO;2

Maddox, R. A. (1980). Mesoscale convective complexes. Bulletin. American. Meteorology. Soc., 61, pp. 1374-1387.

Maadox, R. A. (1983). Large Scale Meteorological Conditions associated whit Midlattitude Mesoescale Convective Complexes. Monthly Weather Rev. Vol. 111, pp. 1475-1493.

Olcina Cantos, J. (2005). La prensa como fuente para el estudio de los tiempos y climas. Revista de Historia Moderna, Instituto Interuniversitario de Geografía. Universidad de Alicante. pp. 185-232.

Riosalido, R., Rivera, A. y Martín F. (1988). Developmen of a mesoescale convective system at Spanish Mediterranean area. Meteosat scientific meeting. Madrid $27-$ 30 septiembre. pp. 378-398.

Riosalido, R., Rivera, A. y Martín F. (1988). Identificación de un Complejo Convectivo de Mesoescala en el área mediterránea española. IV Asamblea Nacional de Geodesia y Geofísica. Madrid.

Riosalido, R., Rivera, A. y Martín León, F. (1989). The life-cycle of a quasistationary Mediterranean Mesoscale Convective System. European Geophysical Soc. XIV. General Assembly. Barcelona.

Riosalido, R. (1990). Caracterización mediante imagines de satélite de los sistemas convectivos de mesoescala durante la campaña Previmet Mediterráneo 89. Segundo Simposio Nacional de Predicción. Madrid 20-22 noviembre. INM. 
Riosalido, R. (1990). Estudio sobre algunos parámetros atmosféricos asociados a la formación y evolución de sistemas convectivos de mesoescala. Segundo Simposio Nacional de Predicción. Madrid 20-22 de noviembre. INM.

Riosalido, R. y Carretero, O. (1998). Sistemas Convectivos de Mesoescala: climatología mediante imágenes de satélite. Rev. Nimbus No 12 .

Rivera, A. y Riosalido, R. (1986). Mediterranean Convective Systems as viewed by Meteosat. A case Study. Proc. 6th Meteosat Scientific Users Meeting. Amsterdam. Vol. 1. pp. 375-388.

Valdés Manzanilla, A. y Barradas Miranda, V.L. (2012). Mesoscale convective systems during NAME. Atmósfera. Vol. 25, №. 2. pp155-170.

Zipser, E.J. (1982). Use of a conceptual model of the life-cycle of mesoscales convective systems to improve very-short-range forecast, in Nowcasting, K. Browning (Ed.), Academic Press, New York, pp. 191-204.

Zipser, E.J. (1987). The evolution and structure of mesoscale convective systems as seen from satellite imagery. Preprints Workshop on satellite and radar imagery interpretations. Reading. EUTMETSAT. 